\title{
BMJ Open Individualisation of drug treatments for patients with long-term conditions: a review of concepts
}

\author{
S Denford, J Frost, P Dieppe, Chris Cooper, N Britten
}

To cite: Denford S, Frost J, Dieppe $\mathrm{P}$, et al. Individualisation of drug treatments for patients with long-term conditions: a review of concepts. BMJ Open 2014;4:e004172. doi:10.1136/bmjopen-2013004172

- Prepublication history for this paper is available online. To view these files please visit the journal online (http://dx.doi.org/10.1136/ bmjopen-2013-004172).

Received 4 October 2013 Revised 19 December 2013 Accepted 27 February 2014

CrossMark

University of Exeter Medical School, Institute of Health Research, Exeter, UK

Correspondence to Dr Sarah Denford; s.denford@exeter.ac.uk

\begin{abstract}
Objectives: Patients and policy makers advocate that drug treatments should be individualised. However, the term is used in a variety of ways. We set out to identify the range of related terminology and concepts in the general field of individualisation, map out the relationships between these concepts and explore how patients' perspectives are considered.
\end{abstract}

Design: We consulted members of an established patient and public involvement group about their experience of medicine taking for long-term conditions and their ideas about individualisation. We then conducted a scoping review of the literature to explore how terms surrounding individualisation of drug treatment are used and defined in the literature, and to explore the extent to which patients' perspectives are represented, with a view to informing future recommendations as to how individualisation can be operationalised.

Methods: We identified relevant literature using a range of search strategies. Two researchers independently extracted definitions of terms using a template. Inductive and deductive methods were used to explore the data.

Results: Definitions were categorised according to the following themes: medical management;

pharmacogenetics, the patient's perspective; interactions between the healthcare provider and patient and management of long-term conditions.

Conclusions: Within the literature reviewed, the involvement of patients in the ongoing management of drug treatment was largely absent. We propose the use of a new term 'mutually agreed tailoring' (MAT). This describes the ongoing pharmacological management of conditions that incorporates patients' specific needs, experiences and existing strategies for using their medications, and the professionals' clinical judgement. This usually includes patients monitoring their symptoms and, with the support of the professional, making appropriate product, dose or timing adjustments as necessary. Our previous work suggests that many patients and doctors are successfully practising MAT, so we suggest that a formal description may facilitate wider utilisation of strategies that will improve patient outcomes.

\section{INTRODUCTION}

Patients with long-term conditions often need to take several drugs to help manage

\section{Strengths and limitations of this study}

- By conducting workshops with a patient and public involvement group and a scoping review, we identified dissonance between lay and professional notions of individualisation.

- Strategies such as the use of a data extraction template and multiple coders were used to minimise risks of bias being introduced into the review.

- We aimed to identify a typology of papers which discussed individualisation, rather than a comprehensive list. It is possible that relevant articles were missed.

their illness. They are required to manage these medications on a daily basis, and thus need to be involved in their treatment. Patients and policy makers ${ }^{1}$ advocate that treatments are individualised, and 'shared decision-making' is advocated, ${ }^{2}$ although the terms individualisation and shared decisionmaking are used in a variety of different ways.

From a recent interview study with doctors we found that, while individualisation was considered to be beneficial, understandings of what it meant were variable. ${ }^{3}$ Methods used to achieve individualised treatment are frequently discussed in relation to making drug treatment decisions (ie, whether the patient should use a specific drug or not). Few doctors discuss the use of strategies to support patients to individualise their own treatments after the consultation by, for example, making sure that the dose and timing of any drug is appropriate for the individual patient. ${ }^{3}$ We set out to explore this concept further, and to identify how the term is used in the literature.

If clinically relevant research is going to help patients manage long-term conditions, then it needs to address their concerns. It is widely acknowledged that research should address issues that are of relevance to patients ${ }^{4}$; however, much research is 
conducted without consulting them. ${ }^{4}$ To try and ensure the relevance of the work reported here to patients, we sought the advice of an established patient and public involvement (PPI) group, which has experience of contributing to all stages of research including question generation. ${ }^{5}$ We asked them what individualisation of drug therapy meant to them, in the context of their own longterm conditions. The group's main points and recommendations are summarised below.

'Individualisation' was seen by our PPI group as a way of potentially minimising the negative impact of burdensome medication regimes. ${ }^{6}$ It occurs when patients are involved in the initial decisions and the ongoing pharmacological management of their conditions. Accordingly, initial treatment decisions should be negotiated between the patient and the general practitioner (GP) after consideration of patients' individual needs, lifestyles, and coexisting conditions and medications. If requested, patients should be given information about the purpose, harms and benefits of particular treatments; however, patients may also research this for themselves. With the support of healthcare providers, patients should also be involved in the ongoing monitoring and adjustment of doses. Members of the group described situations in which they had increased or decreased the dosage of particular treatments until it suited their individual needs, corroborating previous research. ${ }^{7}$ The role of the doctor should be to set safe parameters within which patients can adjust their medications, to inform patients what to expect when taking a new drug and to highlight potential side effects that would require immediate action (eg, which side effects should lead to the immediate discontinuation of the treatment and which should be tolerated if possible). The group recognised limitations to this description of individualisation. It was noted that not all patients want their treatments to be individualised in this way. Second, patients described the considerable level of involvement required of the patient. It was acknowledged that not all patients will be motivated to make such an effort. Third, with this

Table 1 Extract of search terms from the scoping search

1 ('n of $1^{\prime}$ adj3(trial* or stud $\left.{ }^{*}\right)$ ).tw.

2 ((individuali* or personali* or tailor $\left.^{\star}\right)$ adj3(medic* or treat* or care or healthcare or therap ${ }^{\star}$ or manag ${ }^{\star}$ or regimen* or drug?)).tw.

3 individualised medicine/

4 (('single participa*' or 'single patient" or 'single case ${ }^{*}$ or 'single subject"' or 'individual participa*' or 'individual patient"' or 'individual case*' or 'individual subject"') adj3(trial* ${ }^{*}$ or stud ${ }^{\star}$ or design*)).tw.

5 'self monitor".tw.

6 (monitor* adj2(their or own or themselves)).tw.

7 ((individually or personally) adj1 tailored).tw.

8 ((patient or person or client) adj1(cent?red or focus?ed or oriented or led)).tw.

9 patient centered care/ approach comes the potential for patients to be left feeling unsupported. Finally, the group recognised that individualisation of treatment is challenging (if not impossible) without continuity of care.

We (the authors of this paper) met to discuss these views in the light of our previous finding that the terms used to describe such activities were varied and confusing, although some doctors appeared to be doing what our PPI group recommends. ${ }^{3}$ We thought that a new term might help define the need and activities identified-that is, 'mutually agreed tailoring' (MAT). The aim of this paper is to explore how other terms surrounding individualisation are used in the published literature, and whether or not they address the issues raised by the PPI group.

\section{OBJECTIVES}

To conduct a scoping review of the literature to (1) identify the range of related terminology and concepts in the general field of individualisation of drug treatment, (2) map out the relationships between all these concepts and (3) to assess the extent to which the ideas presented in the literature reflect the needs identified by our PPI group.

\section{METHODS}

A broad scoping exercise was conducted with the objectives of providing a preliminary map of the literature (eg, numbers and types of papers); to assist in defining parameters for a full review (eg, populations, medical specialties, methodologies, outcomes) and to assess the feasibility of conducting a systematic review. ${ }^{8}$

Preliminary search terms were developed by the research team to reflect the core concepts identified from our previous qualitative study with physicians, and our discussions with the PPI group, about the methods used to individualise treatments. ${ }^{3}$ This included the terms tailored, drug monitoring, personalised and dose adjustment, and a protocol for the review was produced.

Database searches were conducted in 2012 (in MEDLINE, MEDLINE in Process, EMBASE, CENTRAL, Conference Proceedings Citation Index-Science, and Social Science and Humanities) using the various terms for individualisation (table 1). The strategies produced in excess of 100000 hits. Papers identified by these searches were collated and three randomly sampled batches of 100 abstracts were independently screened by two of the researchers, and consensus was achieved through discussion with the wider team.

The purpose of screening was to identify a typology of papers which discuss individualisation.

Abstracts were excluded if they were not specifically about individualisation (eg, were about shared decisionmaking in its broadest sense or about personalised care budgets). This produced 22 included papers that were charted to demonstrate the breadth and depth of the literature. ${ }^{8}$ As the purpose of the review was to identify 
concepts, it was not necessary to conduct quality appraisal.

The scoping review revealed the complexity of the literature. Many papers about individualisation are commentaries or opinion pieces, written from a particular author's perspective, or contribute to a discourse or ideology and were important to capture. It was not possible to identify a keyword or set of keywords which produced a clearly delineated set of papers about individualisation, which indicated a lack of conceptual clarity or maturity of the literature which constrains the possibility of conducting a systematic review of individualisation of drug treatments, and no existing systematic reviews of the topic were identified.

The scoping review identified 16 authors (table 2) who had either contributed a key paper or presented a particular perspective that warranted further exploration. ${ }^{9}$ Author citations were searched, and authors were contacted and asked if they could suggest any other papers relevant to the literature search. ${ }^{10}$ Full texts were retrieved for 68 articles for further screening which illustrated the diversity of interests (medical education, philosophy and clinical practice) and perspectives (humanism, cyber science and evidence-based policy). A clear champion of individualisation was not identified.

Pooling the scoping and author reviews produced a total of 90 papers for analysis.

\section{Data extraction}

The data were initially tabulated in a simple matrix, which facilitated a preliminary exploration of the constituents, contexts and themes (table 3). Each of the researchers read the definitions and contextual data and identified the key constructs of individualisation, which informed the data extraction template. Two researchers independently extracted the definitions of individualisation, while the remaining team members extracted

Table 2 Author search and number of abstracts identified

\begin{tabular}{|c|c|c|c|}
\hline Author & $\begin{array}{l}\text { Number } \\
\text { of articles } \\
\text { retrieved }\end{array}$ & Author & $\begin{array}{l}\text { Number } \\
\text { of articles } \\
\text { retrieved }\end{array}$ \\
\hline $\begin{array}{l}\text { Jeffrey } \\
\text { Aronson }\end{array}$ & 369 & $\begin{array}{l}\text { Gordan } \\
\text { Guyatt }\end{array}$ & 1120 \\
\hline Cynthia Boyd & 211 & $\begin{array}{l}\text { Cameron } \\
\text { Hay-Rollins }\end{array}$ & 22 \\
\hline Alan Cribb & 153 & Rob Horne & 88 \\
\hline Glynn Elwyn & 243 & Lez Irwig & 293 \\
\hline Vicki Entwistle & 124 & $\begin{array}{l}\text { Richard } \\
\text { Kravitz }\end{array}$ & 237 \\
\hline Terri Fried & 116 & $\begin{array}{l}\text { David Le } \\
\text { couteur }\end{array}$ & 190 \\
\hline Paul Glasziou & 441 & Mary Tinetti & 182 \\
\hline $\begin{array}{l}\text { Francis } \\
\text { Griffiths }\end{array}$ & 204 & & \\
\hline
\end{tabular}

definitions for $10 \%$ of the papers, and all researchers reviewed and agreed upon the extracted data.

\section{Data analysis}

Definitions from the 90 papers were the units of analysis, and the categories from the data extraction template provided an analysis framework. ${ }^{11}$ Concurrent thematic analysis facilitated a more nuanced exploration of the data. $^{12}$ The researchers categorised the definitions according to the following themes: medical management of conditions, pharmacogenetics, the patients' perspective, interactions between healthcare providers and patients and long-term management of conditions.

\section{RESULTS}

Terms pertaining to individualisation in its broadest sense are used inconsistently to refer to a multitude of factors. The terms personalised and individualised are often used interchangeably, and there appears to be no evidence that either term is used to refer to particular qualities more than the other. Many papers present definitions that are vague-it is common to find definitions such as "Personalisation simply means the right drug for right patient at the right time". ${ }^{13}$ Tautological definitions are common, and a lack of context or reference can undermine utility. Other definitions are polemical, arguing that personalisation is needed without defining the concept or clarifying how it is achieved.

As personalisation and individualisation are often used interchangeably we will use the term individualisation.

\section{Medical management}

Some definitions of individualisation focus exclusively on the medical management of conditions. Treatments are considered to be individualised if patients are divided into subgroups (based on a range of factors), or if comorbidities are considered. In this group of definitions, individualisation tends to be considered in relation to the prescribing of treatments rather than the long-term management of the condition. The perspective of the patient is not considered. For some, evidencebased medicine (EBM) and governance frameworks are seen to be synonymous with individualisation, as the healthcare provider has to identify the guideline or treatment option that best suits the individual patient. In contrast, others argue that EBM is the antithesis of individualisation, stating that each patient is unique and cannot be forced into standardised guidelines.

The following definition by the Academy of Medical Science describes individualisation as a 'medical model'. This is an approach to healthcare in which the focus is on the treatment of the underlying pathology of the disease, negating factors such as the influence of the environment and preferences of the patient:

[Personalisation is] a medical model in which medical care is customised to individual patients ${ }^{14}$ 


\section{Table 3 Extract from data matrix}

\begin{tabular}{|c|c|c|c|c|}
\hline Author(date) & Definition & Terms used & $\begin{array}{l}\text { Constituents of } \\
\text { definition }\end{array}$ & $\begin{array}{l}\text { Researcher } \\
\text { theme }\end{array}$ \\
\hline Bates (2010) & $\begin{array}{l}\text { "Personalized medicine refers to the tailoring of } \\
\text { medical treatment to the individual } \\
\text { characteristics of each patient. It does not } \\
\text { literally mean the creation of drugs or medical } \\
\text { devices that are unique to a patient but rather } \\
\text { the ability to classify individuals into } \\
\text { subpopulations that differ in their susceptibility } \\
\text { to a particular disease or their response to a } \\
\text { specific treatment. Preventive or therapeutic } \\
\text { interventions can then be concentrated on those } \\
\text { who will benefit, sparing expense and side } \\
\text { effects for those who will not" }\end{array}$ & Personalised & $\begin{array}{l}\text { Subgroups } \\
\text { Preventative } \\
\text { medicine } \\
\text { Minimising side } \\
\text { effects }\end{array}$ & $\begin{array}{l}\text { Medical } \\
\text { management }\end{array}$ \\
\hline Luijks (2012) & $\begin{array}{l}\text { "GPs agreed on the need to adapt management } \\
\text { of multimorbidity to personal circumstances of } \\
\text { these patients, such as vitality, personal } \\
\text { preferences (for example retaining } \\
\text { independence as the ultimate goal) and } \\
\text { socioeconomic conditions. They stressed the } \\
\text { importance of tailoring care to the individual and } \\
\text { tried to understand the meaning of illness for a } \\
\text { person" }\end{array}$ & Individualised & $\begin{array}{l}\text { Multimorbidity } \\
\text { management } \\
\text { Personal } \\
\text { circumstances } \\
\text { Patient preferences } \\
\text { Meaning of illness } \\
\text { for the individual }\end{array}$ & $\begin{array}{l}\text { Consideration of } \\
\text { patient factors }\end{array}$ \\
\hline
\end{tabular}

Treatments are individualised to subgroups of the population based on different factors that influence susceptibility to a certain condition. Definitions vary with regard to the factor(s) used to define subgroups; they may include genetics, age, family history or gender. The focus is on maximising the therapeutic effectiveness, rather than incorporating the patient's preferences and lifestyles. Treatments are designed to reduce the risk associated with drug treatment, to maximise the benefits and minimise the harms from the perspective of the prescriber:

Personalized Medicine refers to the tailoring of medical treatment to the individual characteristics of each patient...to classify individuals into subpopulations that differ in their susceptibility to a particular disease or their response to a specific treatment. Preventative or therapeutic interventions can then be concentrated on those who will benefit, sparing expense and side-effects for those who will not ${ }^{15}$

For some, this is achieved through EBM and the skill of the practitioner. Rather than categorising patients at the cellular level (as is the case with pharmacogenetics), EBM focuses on the categorisation of patients based on age, gender and family history. The healthcare provider plays a significant role in eliciting and balancing multiple factors to effectively diagnose and treat the patient. However, the perspective of the patient is still absent:

From the time of Hippocrates and to the present day all medical students are diligently taught to elicit individual patients' family history, past medical history and corroborate this with clinical symptoms and signs...Thus essentially EBM is truly the 'personalised medicine.' It is the acceptable form of 'good medical practice'

\section{Pharmacogenetics}

Among the literature that we reviewed, the development of pharmacogenetics was dominant and frequently considered to be the ultimate form of individualisation. This allows for the identification of subgroups of patients likely to respond to treatment based on variations in genetics:

Using high throughput array technologies, it is possible to analyse thousands of genes or gene products simultaneously, resulting in an individual gene or gene expression profile (signature). These data increasingly allow to define the individual risk for a given disease and to predict the individual prognosis of a disease as well as the efficacy of therapeutic strategies (individualized medicine $)^{17}$

In contrast to the quote above in which EBM is considered to be truly personalised medicine, the quote below describes EBM as counter to individualised medicine. This is due to the perception that the prioritisation of science undermines the 'personal' element that was essential in traditional medical practice. Pharmacogenetics is seen as the solution to repersonalising medicine on a scientific basis by combining the personal (but largely nonscientific) methods of old with evidence-based (but not personal) methods: 
Personal medicine was lost with the advent of scientific, evidence-based medicine. This loss is deplored by many patients and is one of the reasons for the attractiveness of alternative medicine. Now, medicine needs to be re-personalized on a scientific basis ${ }^{18}$

However, as we discuss below, some writers describe pharmacogenetics and EBM as reductionist and suggest that they depersonalise medicine.

The concept of 'preventative healthcare' features in a number of articles about pharmacogenetics. This refers to screening and other procedures that are undertaken to predict and prevent (or delay) a disease before it occurs. As preventative procedures occur before the onset of the condition, the patient has to be proactive in requesting the necessary course of action. In the following definition, Pfaff $e t a l^{19}$ equate personalised medicine with proactive and preventative medicine:

Personalized medicine enables patients to be more proactive. Proactive managed care means screening, early treatment, prevention, the use of information technology, electronic medical records and decision-making tools

Similarly, the definition provided by the European Science Foundation (ESF) also refers to proactive, preemptive and preventative healthcare:

In essence, personalised medicine represents a shift from reactive medicine to proactive, pre-emptive and preventive healthcare ${ }^{20}$

In that report, the authors go on to describe 'proactive P4 medicine' which refers to healthcare that is predictive, preventive, personalised and participatory. ${ }^{19} \mathrm{~A}$ discussion of the differences between the terms proactive, pre-emptive and preventative is beyond the scope of this paper; however, all refer to actions taken by the patient or the healthcare provider to predict and prevent the onset of a disease. Participatory in the sense used by ESF has a similar meaning to the term 'responsibilisation' (see below) as suggested by the Nuffield Council on Bioethics. $^{21}$

While some authors criticise pharmacogenetics for ignoring the impact of the natural and social environment, lifestyle features strongly in some of the longer, more comprehensive definitions of pharmacogenetics such as that provided in the report by the ESF:

Personalised medicine...seeks to integrate data on the entire dynamic biological makeup of each individual as well as the environmental and lifestyle factors that interface with this makeup to generate a complex, individual phenotype $^{20}$

The narrow focus on pharmacogenetics, and the view that this alone will lead to ultimate individualised treatment is considered by some to be unwarranted and counterproductive:
We still lack even a basic framework that permits the multiple patient attributes that influence the effect of treatment -. 'pharmacogenomic exceptionalism'-the notion that genetic information is uniquely important in determining the risks and benefits of treatments-is clearly unwarranted and counterproductive to the broadly shared goal of tailoring care to individuals ${ }^{22}$

While recognising the importance of the environment and the dangers of a narrow focus on pharmacogenetics, these two definitions focus on the influences of the natural environment on the patient's responses to treatment. This is considerably different to the definition proposed by Burgener $e t a l^{23}$ in which the patient's social environment is emphasised, although it is unclear how this should inform treatment decisions:

[treatment should be] based on the patient's disease, physical and psychological needs, family history, life events, habits, friends, hobbies etc. Special emphasis should be put on the patient's own needs and preferences. The focus on individuality includes past environmental and cultural influences that affect the person's response pattern.

\section{The patient's perspective}

Pharmacogenetics and online genetic tests are not 'personalized' but stratified, information is less a firm prediction and more an estimation of risk, and increased 'choice' can be anxiety provoking, confusing and leave an individual feeling abandoned and uncared for. ${ }^{24}$

Some writers are critical of the idea that medically focused treatment, such as pharmacogenetics, and EBM have anything to do with individualisation. They argue that individualisation requires patients' perspectives, values, preferences and experiences to be considered. This would require patients to be actively involved in their care, and healthcare providers treating the whole person-not just their disease. However, aspects of definitions that focus on the preferences of patients tend to focus on social or lifestyle choices, and not the management of drugs. These articles are frequently polemical and do not explain how individualisation could be achieved.

The following quote is taken from a qualitative study of GPs. This particular quote is presented in that paper under the heading of 'individualisation'. ${ }^{25}$ It describes how GPs see individualisation as the inclusion of a range of factors such as the patients' preferences in treatment decisions. However, the authors do not contextualise this, and it is not clear if patients' values have to be specific to their health or if a broader range of values are considered. While emphasising the importance of tailoring care to the individual, the authors do not provide any suggestions as to how to elicit the meaning of the illness for the person, or how this might inform treatment decisions: 
GPs agreed on the need to adapt management of multimorbidity to personal circumstances of these patients, such as vitality, personal preferences (for example retaining independence as the ultimate goal) and socioeconomic conditions. They stressed the importance of tailoring care to the individual and tried to understand the meaning of illness for a person ${ }^{25}$

As discussed above, authors take different views as to whether EBM or pharmacogenetics is the ultimate form of individualised treatment. However, for others pharmacogenetics and EBM depersonalise medicine; they suggest that patient involvement is the only way to really personalise treatment:

As our medical decisions become more and more standardized and codified, we should take care to ensure that critical therapeutic choices are not based exclusively on formal guidelines. Many decisions need to be individualized, especially when they involve choices between possible outcomes that may be viewed differently by different patients $^{26}$

This is not to say that patients' preferences are not considered in EBM. Some authors writing from an EBM perspective argue that EBM does incorporate the views of the patient. This usually refers to the extent to which patients want to be involved in treatment decisions, or if the patient has a preference for a specific treatment over another. How the patient uses the treatment on a day to day basis is rarely considered.

EBM is individual patient oriented and clearly recognises individual needs. The process of individualised EBM decision making uses guides to address the credibility of subgroup analyses, approaches to incorporating individual patient values and preferences, and individualized RCTs (N-of-1 RCTs) ${ }^{27}$

The science versus art discourse is a strong theme in the literature. While in the quote above, EBM is seen as individualised, other authors consider approaches such as 'the art of medicine' to be the only approach capable of individualising treatment. This is an approach to medical practice that emphasises the need to treat the patient with empathy and compassion. There is a temporal perspective to this argument which reflects changes in medical practices. Tutton ${ }^{28}$ describes how the development of laboratory sciences was contested by physicians of the time, who feared that its progression would eradicate patient individuality. Despite the shared use of the term personalised, the two meanings of the term are conflicting:

During the latter part of the 19th century, as laboratory sciences mobilized support from various quarters around their promise to revolutionize medicine, physicians contested this future. They stressed the 'art' of medical practice, which was founded upon a privileged epistemology of patient individuality in contradistinction to the universalization of knowledge represented by the laboratory sciences. This rhetoric conjured up an image of an individualized medicine that was part and parcel of elite physicians' professional identity during that period in Britain $^{28}$

Generally, the literature is vague in the way in which individualisation is described in relation to eliciting the patient's perspective. While it is often stated that the patients' needs and wants have to be considered, these are typically neither qualified nor quantified in relation to either healthcare or other aspects of their lives. In a report undertaken by the National Health Service (NHS) National Prescribing Centre entitled 'Moving towards Personalised Medicines Management' Picton ${ }^{29}$ suggests that medicines are:

personalised to the needs and wants of each individual, especially the most vulnerable and those in greatest need, providing access to services at the time and place of their choice

Without clarifying what personalisation is, the report suggests various examples of ways in which it can be achieved in clinical practice. One example is the use of medication use reviews (MURs) during which healthcare providers review the patient's medicines in order to maximise the effectiveness of the treatment plan and identify any unnecessary medications. The extent to which MURs incorporate the 'needs and wants' of each individual is unclear. It is also hard to see the 'individualised element' in some of their other suggestions for achieving individualised treatment.

In a report written for the Nuffield Council on Bioethics, a number of uses of the term personalised are discussed. The authors of the report are cautious about the use of the term for a number of reasons; one being that "the term personalisation, despite, or perhaps because of its obvious rhetorical appeal and widespread use in several fields of policy, is ambiguous and has many different meanings and implications". ${ }^{21}$ The report provides four uses of personalisation and acknowledges that each use of the term could potentially conflict with another (as is the case in the following two definitions). In the two uses of the term presented below, patient involvement is dominant. Personalisation is seen as being holistic care, incorporating patients' preferences and lifestyles. No recommendations are provided for how this may be achieved. In the first sense, personalisation is:

Management or treatment that is personalised in the sense of treating each individual as a 'whole person' and being respectful of their particular wishes, worldview, lifestyle, and health status overall for example (which might of course include wishes not to take responsibility for managing their own care).$^{21}$ 
In the second sense, personalisation is seen to be the act of encouraging the patients to be active managers of their care (to avoid misunderstanding, the authors of the report chose to use the term 'responsibilisation' instead of personalisation when discussing this issue). However, this refers more to the ability of the patients to manage healthcare appointments and take medication as prescribed than their involvement in drug treatment decisions:

Medical care that is personalised in the sense that more responsibility for management of healthcare is primarily laid on or taken by individuals or their carers rather than on medical professionals ${ }^{21}$

The other two uses of the term presented in the report focus less on the patient and refer to technologies (such as pharmacogenetics) or to patients as consumers of healthcare.

In the group of definitions in which the patients' perspectives are considered, authors generally refer to individualised care or healthcare. For these authors, individualised care is not specific to drug treatment (in some cases, not about drug treatment at all). For example, in the nursing literature, individualised care results when the nurse:

Knows the patient as a unique individual, and tailors nursing care to a patient's experiences (including events associated with illness, home, work and leisure); behaviours (including physical indicators and preferred coping strategies); feelings; and perceptions (including meanings ascribed to experiences and interpretations of events) ${ }^{30}$

In a discussion paper, Cribb and Owens ${ }^{31}$ distinguish personalised medicine from personalised healthcare; the former focusing on medical (including drug) treatment and the latter incorporating patients' preferences. Cribb and Owens argue that personalisation is an 'orchestrating label' under which involvement and partnership are subsumed. Personalisation is used in the literature to refer to a number of things (centring on patient inclusion) that are considered to be important in clinical practice. This has resulted in a situation in which terms have lost all meaning and are simply vague. Cribb and Owens differentiate between personalised medicine (which takes into account the biological characteristics of the patient being treated) and personalised healthcare (which incorporates individual preference). The authors suggest that policy documents often promise to achieve personalisation (referring to both elements), despite the two not always being complementary. ${ }^{31}$

\section{Interactions between healthcare providers and patients}

Interactions between healthcare providers and patients only feature in a small number of definitions and are usually one aspect of a more complex definition. For example, Moldrup ${ }^{32}$ refers to an "individualised indication arising through a dialogue between doctor and patient" as being one element of individualisation.

Initiatives such as education, information sharing, communication and relationship building are all mentioned as promoting individualisation; however, such initiatives are rarely specific to the management of drug treatments. In the following definition, Hoffman discusses how treatment becomes individualised by the doctors integrating many different elements relevant to the management of conditions. Shared decision-making is then used to identify which goals the patient wishes to pursue:

Clearly, the concept of individualized medicine requires a holistic and integrative approach... The doctor's task will be to condense all of these aspects into straightforward therapeutic options which can be discussed with the patient. In a shared decision process, it will ultimately be the patient's choice as to what therapeutic goals will be primarily pursued ${ }^{33}$

While consideration of interactions between healthcare providers and patients features strongly in papers discussing concepts such as shared decision-making and patient-centred care, which are not specifically about drug treatment, this is absent from the majority of definitions of individualisation that we reviewed.

\section{Long-term management of conditions}

Many of the definitions provided above focus on individualisation as a one off prescribing decision, not as part of a process. However, long-term conditions are likely to change over time, and symptoms may improve or worsen as patients respond to treatment or as the condition progresses. Treatments need to be adapted to reflect such developments. For some writers, this adaptation of treatment in response to changes in the patient has been termed individualisation:

The idea of 'personalized medicine' has seized the imagination of many medical researchers. Instead of 'one pill cures all', personalized medicine offers a strategy, a list of treatment recommendations that depend on the genetic makeup of the individual patient... But each individual's germ-line genome is fixed over her lifetime, while everything else changes, including her state of health or illness, and response to treatments. ${ }^{34}$

Previous research has found that patients monitor symptoms and modify medications accordingly. Terms to describe this process include monitoring, dose adjustment and self-management. Monitoring is defined by Glasziou et $a l^{35}$ as:

Periodic measurement that guides the management of a chronic or recurrent condition. It can be done by clinicians, patients, or both

While monitoring itself is rarely referred to as individualisation, technological devices to support self-monitoring 
and dose titration are often considered to be promoting individualised healthcare:

The technology of personalised health care is based principally on the patient's use of portable or implantable systems that monitor a variety of physiological parameters, such as twenty-four-hour heart and respiratory $\operatorname{rate}^{36}$

The focus is very much on the monitoring of physical parameters, such as blood pressure, and not on the patient's experiences. It is likely that any adjustments based on these measurements are exclusively made by healthcare providers. In some cases, treatment targets are fixed, and the patient adjusts the dose or duration of the treatment until the target is achieved. ${ }^{37}$ In other cases, the treatment target is individualised to each patient. For example, Strain ${ }^{38}$ identified individualised glycated haemoglobin (HbA1c) targets for elderly patients with diabetes based on patients' age, frailty status, comorbidities and baseline HbA1c values. Here, patients are required to titrate their treatment doses to achieve the desired level.

Although there is room for patients to be active in this process, it is usually the healthcare provider who has the ultimate control. However, others argue that the involvement of the patient is crucial in the management of the condition. In an editorial, Heisler ${ }^{39}$ suggests that:

Patients interpret, evaluate, and accept or reject doctors' recommendations on the basis of their personal experience of their illness in the context of their lives; patients often cooperate only with recommendations that coincide with their own goals and ideas about their illness. By actively participating, patients can communicate their concerns, lifestyle, and priorities to the provider, enabling their treatment regimen to be tailored to their individual needs, values, and goals, thus maximizing the likelihood of adherence.

This author then discusses an observational study in which it was suggested that monitoring only leads to improved outcomes if this is combined with a good communication strategy between the patient and the healthcare provider. ${ }^{40}$

There are interventions in which patients are invited to be involved in decisions about the goals and targets for their pharmacological treatment. McManus et at $t^{11}$ described an intervention consisting of telemonitoring and self-management in the control of hypertension (the TASMINH2 trial). Patients in this trial were taught to monitor their symptoms using a telemonitoring device that transmitted results to the research team. A traffic light system indicated whether the reading was above, below or on target. If a patient was above or below target, they were asked to adjust treatment doses in accordance with a preapproved titration schedule. ${ }^{41}$ Interventions of this kind may be considered to be similar to N-of-1 trials, which are: crossover studies performed within a single individual. A typical n-of-1 trial will implement aspects of a group-level crossover trial, but on an individual (patient) level. For each patient, his/her individual treatment effect (ITE) is estimated by the difference between the average outcome observed during time periods (episodes) the patient received treatment $\mathrm{A}$ and treatment $\mathrm{B}$. Each patient serves as his/her own control, and the ITE obtained from the trial is directly applicable to the specific patient being treated ${ }^{42}$

$\mathrm{N}$-of-1 trials are a methodology, and not an accepted form of clinical practice. Having said this, there is anecdotal evidence that healthcare providers are using informal N-of-1 trials with patients to identify optimal treatment. They are commonly referred to as individualised medication effectiveness tests ${ }^{43}$ and involve a process of trying a treatment or dose, monitoring, adjusting as necessary and remonitoring until the 'best' dose has been achieved. As with monitoring interventions, N-of-1 trials may be completely controlled by healthcare providers, with the patent having no input at all. However, there is room in such tests for patients to have considerable involvement in deciding treatment goals and targets, and in monitoring dose adjustment.

\section{DISCUSSION AND CONCLUSIONS}

From sampling the broad body of literature, we conclude that terms surrounding individualisation are used inconsistently and interchangeably to refer to a multitude of concepts. There does not appear to be any evidence that any one term is used to refer to specific elements of individualisation more than any other. In some cases, definitions of the same term are contradictory. For example, some definitions focus exclusively on managing the medical aspects of the patients' condition, without considering the long-term impact on the patient. These definitions tend to centre on a technology or governance issue, such as pharmacogenetics or evidence-based guidelines. Most start from a clinical perspective and focus on a single consultation. Other authors argue that such technologies actually depersonalise medical care and suggest that patients' perspectives must be considered. However, these articles are typically polemical, with authors arguing that treatments should be individualised, without clearly stating what this is, or how it can be achieved. These findings suggest that generic terms such as individualised should be avoided, and that more specific terms, such as pharmacogenetics, should be used whenever possible. Existing terms are not available for every element of individualisation discussed in this review, thus new terms will be needed.

Patients often state that they want to be involved in the long-term management of their drug treatments, and some of them are already actively modifying their drug treatments to suit their own requirements. ${ }^{7}$ In a previous qualitative study, we found that healthcare providers are individualising treatments in their own way. ${ }^{3}$ 
For example, doctors reported the use of graph paper to help patients to monitor and track changes in their symptoms, and to adjust medication accordingly. However, strategies of this kind were not discussed in any of the literature we reviewed. Indeed, the 'patient's perspective' was completely absent from much of the literature purporting to be about individualisation (eg, pharmacogenetics). Some of the approaches presented under the heading 'long-term management of conditions' have the potential to support patients to modify their medications over time; however, even among this subgroup of papers, there is considerable variation in the approaches discussed and the terms used to describe them. Such approaches, while potentially promising, tend to be modifications of research methods (such as informal N-of-1 trials) which may lack clinical utility. There is clearly a need for further research to be conducted in this area, to develop strategies to support patients and practitioners to safely modify treatments to meet individual needs.

This is particularly true when considering multimorbidity and polypharmacy. In a recent King's Fund report, the challenges of treating patients with multimorbidity are discussed. ${ }^{44}$ The authors differentiate between appropriate and problematic polypharmacy-the former referring to the necessary treatment of complex patients with multiple conditions, the latter to inappropriate treatment. The main argument of the report is that further research is necessary to make all polypharmacy appropriate. However, because each patient is individual - with individual conditions, responses, lifestyles, needs and wants-it is difficult to develop an evidence base for treating multimorbidity that suits each individual. The King's Fund calls for the development of systems that optimise medication use so that people gain maximum benefit with the least amount of harm and waste. This would necessarily require the patient's active involvement. We suggest that MAT could be a useful term to describe one such system. It refers to the ongoing pharmacological management of conditions that incorporates patients' specific needs, experiences and any existing strategies for using their medications, and the professionals' clinical judgement. MAT would usually involve patients monitoring their symptoms, with the support of the professional, and making appropriate product, dose or timing adjustments as necessary. As there is evidence that patients ${ }^{7}$ and healthcare providers $^{3}$ are already attempting to modify doses of treatments to suit individual needs, we suggest that further research looking at strategies to achieve MAT could be beneficial. This may involve strategies such as those mentioned in our previous study, ${ }^{3}$ and may also draw on the literature presented in the present study. For example, informal N-of-1 trials may also be a suitable strategy by which MAT is achieved.

At present, there is a lack of consistency in the use of the term individualisation in the literature. For many, individualisation of treatment means pharmacogenetics.
Using the term MAT to refer to monitoring and modification of pharmacological treatment will avoid this connotation, thus improving the extent to which patients and practitioners can discuss strategies to achieve MAT.

Acknowledgements The authors would like to thank Jenny Lowe for supporting the searching phase of the review. The authors would also like to thank the following members of the Peninsula patient involvement group for taking the time to share their invaluable advice: Stephanie Jibson, Nigel Pyart, Faith Harris-Golesworthy, Jo Welsman, Shirley Stevens, Pippa McGuire, Sue Lethbridge, Lynn Tatnell, Heather Bolt and Jim Harris.

Contributors The analysis was completed by SD and JF, with considerable input from PD, CC and NB. The manuscript was written by SD with feedback from JF, PD, CC and NB. All authors were involved in the design of the study and approved the final version of the manuscript.

Funding This article presents independent research funded by the National Institute for Health Research (NIHR) Collaboration for Leadership in Applied Health Research and Care (CLAHRC) for the South West Peninsula.

\section{Competing interests None.}

Provenance and peer review Not commissioned; externally peer reviewed.

Data sharing statement Full dataset is available from the corresponding author at s.denford@exeter.ac.uk

Open Access This is an Open Access article distributed in accordance with the Creative Commons Attribution Non Commercial (CC BY-NC 3.0) license, which permits others to distribute, remix, adapt, build upon this work noncommercially, and license their derivative works on different terms, provided the original work is properly cited and the use is non-commercial. See: http:// creativecommons.org/licenses/by-nc/3.0/

\section{REFERENCES}

1. Department of Health. Equity and excellence. Norwich: Liberating the NHS, 2010.

2. Politi C, Dizon D, Frosch DL, et al. Importance of clarifying patients desired role in shared decision making to match their level of engagement with their preferences. BMJ 2013;347:f7066.

3. Denford S, Frost J, Dieppe P, et al. Doctors' understanding of individualisation of drug treatments: a qualitative interview study. BMJ Open 2013;3:e002706.

4. Chalmers I, Glasziou P. Avoidable waste in the production and reporting of research evidence. Lancet 2009;374:86-9.

5. Whear R, Thompson-Coon J, Boddy K, et al. Establishing local priorities for a health research agenda. Health Expect 2012 doi:10.1111/hex.12029

6. May C, Montori V, Mair F. We need minimally disruptive medicine. BMJ 2009;12:339.

7. Pound P, Britten N, Morgan M, et al. Resisting medicines: a synthesis of qualitative studies of medicine taking. Soc Sci Med 2005;61:133-55.

8. Armstrong R, Hall BJ, Doyle J, et al. Cochrane update. 'Scoping the scope' of a Cochrane review. J Public Health (Oxf) 2011;33:147-50.

9. Booth A. Unpacking your literature search toolbox: on search styles and tactics. Health Info Libr J 2008;25:313-17.

10. Uddin S, Hossain L, Rasmussen K. Network effects on scientific collaborations. PLoS ONE 2013;8:e57546.

11. Ritchie J, Spencer L. Qualitative data analysis for applied policy research. In: Bryman A, Burgess RG. eds. Analysing qualitative data. New York: Routledge, 2000:173.

12. Miles MB, Huberman AM. Qualitative data analysis: an expanded sourcebook. 2nd edn. Thousand Oaks: Sage Publications, 1994.

13. Szefler SJ. Personalised medicine for asthma management in pregnancy. Lancet 2011;378:963-4.

14. The Academy of Medical Sciences. Realising the potential of stratified medicine. London: AMS, 2013.

15. Personalized Medicine Coalition. 2013. http://www. personalizedmedicinecoalition.org/ (accessed Jul 2013).

16. Kumar D. The personalised medicine. A paradigm of evidence-based medicine. Ann Ist Super Sanita 2011;47:31-40.

17. Blum HE. Individualized medicine 2010. J Cell Mol Med 2010;14:2257-63. 
18. Fierz W. Challenge of personalized health care: to what extent is medicine already individualised and what are the future trends. Med Sci Monit 2004;10:111-23.

19. Pfaff H, Driller E, Ernsmann N, et al. Standardization through individualization in care for the elderly: proactive behaviour through individualized standardization. Open Longev Sci 2010;4:51-7.

20. European Science Foundation. Personalised medicine for the European citizen: towards more precise medicine for the diagnosis, treatment and prevention of disease. Strasbourg, France: ESF, 2012.

21. Nuffield Council on Bioethics. Medical profiling and online medicine: the ethics of personalized healthcare in a consumer age. Oxford: Nuffield Council on Bioethics, 2010.

22. Kitsios GD, Kent DM. Personalised medicine: not just in our genes. BMJ 2012;344:e2161.

23. Burgener SC, Shimer R, Murrell L. Expressions of individuality in cognitively impaired elders: need for individual assessment and care. J Gerontol Nurs 1993;19:13-22.

24. Corrigan O. Personalized medicine in a consumer age. Curr Pharmacogenomics Person Med 2011;9:168-76.

25. Luijks HD, Loeffen MJ, Lagro-Janssen AL, et al. GPs' considerations in multimorbidity management: a qualitative study. Br J Gen Pract 2012;62:e503-10.

26. Kassirer JP. Incorporating patients' preferences into medical decisions. N Engl J Med 1994;330:1895-6.

27. Bassler D, Busse JW, Karanicolas PJ, et al. Evidence-based medicine targets the individual patient, part 2: guides and tools for individual decision-making. Evid Based Med 2008;13:130-1.

28. Tutton R. Personalizing medicine: futures present and past. Soc Sci Med 2012;75:1721-8.

29. Picton C. Moving towards personalizing medicines management. Liverpool: National Prescribing Centre, 2008. http://www.npc.nhs.uk resources/personalising_medicines_management_web.pdf (accessed Dec 2013).

30. Radwin LE, Alster K. Individualized nursing care: an empirically generated definition. Int Nurs Rev 2002;49:54-63.

31. Cribb A, Owens J. Whatever suits you: unpicking personalization for the NHS. J Eval Clin Pract 2010;16:310-14.

32. Moldrup C. Beyond personalized medicine. Per Med 2009;6:231-3.
33. Hoffmann $\mathrm{W}$, Krafczyk-Korth J, Valzke $\mathrm{H}$, et al. Towards a unified concept of individualized medicine. Per Med 2011;8:111-13.

34. Lavori PW, Dawson R, Rush AJ. Flexible treatment strategies in chronic disease: clinical and research implications. Biol Psychiatry 2000;48:605-14.

35. Glasziou P, Irwig L, Mant D. Monitoring in chronic disease: a rational approach. BMJ 2005;330:644-8.

36. Vardos P. Personalised health care: an emerging aim. Hellenic $J$ Cardiol 2008;49:453.

37. Mangia A, Minerva N, Bacca D, et al. Individualized treatment duration for hepatitis $C$ genotype 1 patients: a randomized controlled trial. Hepatology 2008;47:43-50.

38. Strain WD, Lukashevich V, Kothny W, et al. Individualised treatment targets for elderly patients with type 2 diabetes using vildagliptin add-on or lone therapy (INTERVAL): a 24 week, randomised, double-blind, placebo-controlled study. Lancet 2013; 382:409-16

39. Heisler M. Actively engaging patients in treatment decision making and monitoring as a strategy to improve hypertension outcomes in diabetes mellitus. Circulation 2008;117:1355-7.

40. Naik AD, Kallen MA, Walder A, et al. Improving hypertension control in diabetes mellitus: the effects of collaborative and proactive health communication. Circulation 2008; 117:1361-8.

41. McManus RJ, Mant J, Bray EP, et al. Telemonitoring and self-management in the control of hypertension (TASMINH2): a randomised controlled trial. Lancet 2010;376:163-72.

42. Gabler NB, Duan N, Vohra S, et al. N-of-1 trials in the medical literature: a systematic review. Med Care 2011;49:761-8.

43. Nikles CJ, Yelland M, Glasziou PP, et al. Do individualized medication effectiveness tests (N-of-1 trials) change clinica decisions about which drugs to use for osteoarthritis and chronic pain? Am J Ther 2005;12:92-7.

44. The King's Fund. Polypharmacy and medicines optimisation. Making it safe and sound. London: The King's Fund, 2013. http://www. kingsfund.org.uk/sites/files/kf/field/field publication file/ polypharmacy-and-medicines-optimisation-kingsfund-nov13.pdf (accessed Dec 2013). 